\title{
Proceeding
}

Supplementary Issue: Autumn Conferences of Sports Science. Costa Blanca Sports Science Events, 18-19 December 2020. Alicante, Spain.

\section{Effects of a kaerobic training plan and diet for a 39- year-old obese patient from UNAH-TEC-Danlí}

\author{
YEFRIK YAIR LANZA-REYES ${ }^{1} \triangle$, RAÚL ORLANDO FIGUEROA-SORIANO², RAUL ANTONIO GAITAN- \\ AMADOR $^{1}$ \\ ${ }^{1}$ Danli Regional Centre, National Autonomous University of Honduras, Tegucigalpa, Honduras \\ 2University Management Board, National Autonomous University of Honduras, Tegucigalpa, Honduras
}

\begin{abstract}
The research was carried out in order to know the blood, physical and psychological chemical effects in the application of a training and diet plan for a 39-year-old patient with obesity from UNAH-TEC Danlí. In this sense, a methodology was established where, based on the systematization of a set of activities related to the different components of the process of physical and educational rehabilitation that aims to create healthy habits, taking into account planned and designed movements specifically to be fit and in good health. The effects were evaluated from a series of blood lipoprotein tests that provided information on metabolic conditions in the human body and also how certain organs function. Consequently, after applying the set of exercise and diet, results were obtained with respect to body composition such as a decrease in the waisthip index, which shows that the cardiac risk decreases with the experiment carried out, a decrease in IMC and body fat of $38 \%$ to $27 \%$, the tests that measure blood chemistry all improved for an optimal functioning of the organism of the patient under study, from the psychological point of view self-esteem improved in the individual analysed after carrying out the experiment, it can be seen that this aspect rose from 24 points to 32 points.
\end{abstract}

Keywords: Overweight; Morbid obesity; Body Mass Index, Folds.

\section{Cite this article as:}

Lanza-Reyes, Y.Y., Figueroa Soriano, R.O., \& Gaitán-Amador, R.A. (2021). Effects of a kaerobic training plan and diet for a 39-year-old obese patient from UNAH-TEC-Danlí. Journal of Human Sport and Exercise, 16(2proc), S837-S847. doi:https://doi.org/10.14198/ihse.2021.16.Proc2.69

Corresponding author. Danli Regional Centre, National Autonomous University of Honduras, Tegucigalpa, Honduras. https://orcid.org/0000-0001-8314-0380

E-mail: yefrik.lanza@unah.edu.hn

Abstract submitted to: Summer Conferences of Sports Science. Costa Blanca Sports Science Events, 25-26 September 2020. Alicante, Spain.

JOURNAL OF HUMAN SPORT \& EXERCISE ISSN 1988-5202

(c) Faculty of Education. University of Alicante

doi:10.14198/jhse.2021.16.Proc2.69 


\section{INTRODUCTION}

This project is of great relevance in its application, at least in this area of knowledge and in UNAH-TEC-Danlí. It consists of the elaboration of a training plan based on Kaerobics and diet for a 39-year-old obese patient in Danli el Paraíso in order to assess the chemical, physical and psychological effects of the sample. This study will be applied with a teacher who belongs to the department of social sciences at UNAH-TEC-Danlí.

It is important to note that the subject under investigation deals with one of the great threats to the preservation of human life, this being the chronic non-communicable disease and one of the risk factors with the highest prevalence worldwide, which makes little effort to be made. by science in terms of contributions from disciplines focused on health, nutrition, psychology and physical activity.

Systematic physical activity should be taken as a regular practice in the lives of all people, without distinction of age, gender, social condition or occupation, due to the endless benefits for people's organic, emotional and psychological health, as that offers tools that allow the individual to face life with a different aptitude, with better health, in this sense, the support of the professional of physical culture through the proposal of programs has conceived a way to give adequate systematic treatment to different groups where people with states of overweight or obesity are focused; however, the particularities of the groups in terms of motivations and health states make diversity and variability play an essential role. In this sense, it is put on trial from the application of a physical activity program based on kaerobics as a variant that combines elements of the martial art Karate with musical rhythm, in this sense, it has been defined with a conceptual interpretation that poses it as the enduring path of the apprentice (beginner, systematic practitioner) of a new art (ability, skill, mastery, trade, technique or practice), which consists of a physical-aerobic and martial activity of repeated movements, it is planned and practiced regularly with the purpose of improving the quality of life and / or keeping the body in optimal physical and mental condition. (González 2016).

It uses combinations with technical elements of Karate-Do, Kick-Boxing and Aerobics on musical rhythms of different genres, created on purpose with sounds that guide the execution of blocking techniques, fists, elbows, knees and kicks, creating coherence between the sound, movements and practitioners, turning the training into a true healthy physical recreation with particularly stimulating and easy-to-learn choreographies.

This is complemented with a specific diet plan, and thus to evaluate the effects that have been caused in a group of adults with an average age of 39 years who are in the environment of the university population of UNAH-TEC-Danlí being in their Most of the teachers, administrative and service personnel in said entity.

These people have been taken into consideration for the study, taking into account that obese people in our centre are not isolated subjects, who can develop and function independently of reality in the community environment that surrounds them. For this reason, in this perspective, it is recurrent in this perspective the search and collective recognition of the existing criteria and evaluations in the group of obese people who work in the centre and not impose what the investigative team can bring; In this sense, a space named labour gymnastics has been created to influence these people and in the future others that may be incorporated. However, the causes that have mobilized the dynamics of the program that has been put into operation have been:

How can we influence if the obese people who work at the UNAH-TEC-Danli centre are not known?

What are the causes that lead to the problems of these people? 
The aim is to identify, elaborate and determine which are the situations, problems, needs and interests existing in each obese person living in the community context (individually), which require a collective response to a greater extent or with greater urgency. Obstacles and resistance of different types that hinder responses to needs are also detected.

\section{Situations or problems identified}

From this approach, it is possible to insert the knowledge of the potentialities that adjoin obese people, taking into account their age range, the tasks that they perform in the centre, recognizing the potentialities that adjoin obese subjects.

Also, the collective search for the objectives or ends to be achieved constitutes a way to achieve the commitment of the people participating in the action so that they are born in the sense of identity and the need for self-management in the search for more appropriate solutions to the characteristics of the pathology (obesity).

The changing, complex, and sometimes contradictory daily life requires more flexible, creative approaches that break with the traditional schemes in the training of Physical Culture teachers and, therefore, it is opportune to mobilize ideas, mentalities and adjust to the new demands of contemporaneity, without losing the focus of the nature of the Honduran personality.

\section{METHODOLOGY}

Effects of a training and diet plan for a patient with obesity of age relative to 39 years of UNAH-TEC-Danlí, is a case study whose design is experimental and in view of this we can state that within the experiment of this inquiry we would carry out a pre-experiment.

\section{Sample}

A sample of 6 subjects is proposed, which are considered in the obesity indexes, among them 4 are women and two men, who were subjected to a Kaerobic training plan for 65 days, accompanied by a diet plan.

\section{Variables}

Kaerobic exercise plan: Systematization of martial physical activity for therapeutic purposes for the improvement of physical condition. (González 2016).

BMI: The Body Mass Index is a measure of association between the weight and height of an individual devised by the Belgian statistician Adolphe Quetelet, which is why it is also known as the Quetelet index.

Blood chemistry: is a series of blood lipoprotein tests that provides information on metabolic conditions in the human body and also how certain organs function. (Oquelí Rosa. 2017).

Self-esteem: it is a set of psychological evaluations about oneself conditioned by thoughts, feelings towards us, referred to our personality or features of our body. (Rubenstein 2016).

Diet: food control system that allows you to organize your intakes based on caloric increase or deficit, as well as the incorporation of different nutrients. 


\section{Process}

The first diagnosis was made from the determination of the IMC, which is determined from the following scale, which is recognized by the World Health Organization since 1998.

Table 1. Classification of nutritional status according to IMC.

\begin{tabular}{lcc}
\hline Classification & IMC $\geq$ & Risk of Morbidity \\
\hline Under weight & $<18.5$ & Low (risk of other clinical problems) \\
Normal & $18.5-24.9$ & Average \\
Overweight & $\geq 25.0$ & \\
Pre obese & $25.0-29.9$ & Increase \\
Obese grade I & $30.0-34.9$ & Moderate \\
Obese grade II & $35.0-39.0$ & Severe \\
Obese grade III & $\geq 40.0$ & Very severe \\
\hline Source: OMS Obesity. Preventing and managing the global epidemic. Report of a WHO Consulting on Obesity. Geneva:
\end{tabular}
WHO/NUT/NCD 1998.

One of the essential values to take into account in our study is the percentage of body fat, in that sense, the following value table will be assumed:

Table 2. Body fat percentage.

\begin{tabular}{lccccc}
\hline Woman & \multicolumn{5}{c}{ Data Percentage } \\
\hline Age & Excellent & Good & Normal & Over eight & Obesity \\
\hline Less than or equal 19 & 17.00 & $17.1-22.0$ & $22.1-27.0$ & $27.1-32.0$ & $\geq 32.1$ \\
$20-29$ & 18.00 & $18.1-23.0$ & $23.1-28.0$ & $28.1-33.0$ & $\geq 33.1$ \\
30-39 & 19.00 & $19.1-24.0$ & $24.1-29.0$ & $29.1-34.0$ & $\geq 34.1$ \\
40-49 & 20.00 & $20.1-25.0$ & $25.1-30.0$ & $30.1-35.0$ & $\geq 35.1$ \\
Greater than or equal 50 & 21.00 & $21.1-26.0$ & $26.2-31.0$ & $31.1-36.0$ & $\geq 36.1$ \\
\hline Men & Excellent & Good & Data Percentage \\
\hline Age & 12.0 & $12.1-17.0$ & $17.1-22.0$ & $22.1-27.0$ & $\geq 27.1$ \\
\hline Less than or equal 19 & 13.0 & $13.1-18.0$ & $18.1-23.0$ & $23.1-28.0$ & $\geq 28.1$ \\
20-29 & 14.0 & $14.1-19.0$ & $19.1-24.0$ & $24.1-29.0$ & $\geq 29.1$ \\
30-39 & 15.0 & $15.1-20.0$ & $20.1-25.0$ & $25.1-30.0$ & $\geq 30.1$ \\
40-49 & 16.0 & $16.1-21.0$ & $21.1-26.0$ & $26.1-31.0$ & $\geq 31.1$ \\
Greater than or equal 50 & \multicolumn{5}{c}{}
\end{tabular}

Table 3. Provide this title in English.

\begin{tabular}{|l|c|c|c|}
\hline \multirow{4}{*}{ Blood chemistry (positive effect) } & \multirow{4}{*}{ HDL Men } & More of 50 & Normal \\
\cline { 2 - 4 } & LDL Men & Less than 50 & Abnormal \\
\cline { 2 - 4 } & \multirow{3}{*}{ Triglyceride Men } & More of 100 & Abnormal \\
\cline { 2 - 4 } & & Less than 100 & Normal \\
\cline { 2 - 4 } & & Less than 150 & Abnormal \\
\cline { 2 - 4 } & Gore of 150 & Abnormal \\
\cline { 2 - 4 } & Glucose Men & Less than 115 & Normal \\
\cline { 2 - 4 } & \multirow{3}{*}{ Cholesterol } & More of 115 & Abnormal \\
\cline { 2 - 4 } & Less than 200 & Normal \\
\cline { 2 - 4 } & \multirow{2}{*}{ Uric Acid Men } & Less than 7 & Normal \\
\cline { 2 - 4 } & More of 7 & Abnormal \\
\hline
\end{tabular}




\section{Rosenberg Self-Esteem Scale}

Indication: Questionnaire to explore personal self-esteem understood as feelings of personal worth and selfrespect.

Coding process: 1.1.1.1.2.1.1.4 Self-esteem (CIPE-a).

Administration: The scale costs 10 items, sentences of which five are stated in a positive way and five in a negative way to control the effect of self-administered acquiescence.

Interpretation:

- From items 1 to 5 . Answers A to D are scored from 4 to 1.

- From items 6 to 10 , responses $A$ to $D$ are scored from 1 to 4.

- From 30 to 40 points: High self-esteem. Considered normal self-esteem.

- From 26 to 29 points: Average self-esteem. It does not present serious self-esteem problems, but it is conveniently improved.

- Less than 25 points: Low self-esteem. There are significant self-esteem issues.

Rosenberg self-esteem scale

The test aims to assess the feeling of satisfaction that the person has with himself.

Please, answer the following sentences with the answers that you consider most appropriate.

A. Strongly agree
B. Agree
C. Disagree
D. Strongly disagree

Table 4. Questionnaire to assess self-esteem.

Items

A $\quad$ B $\quad$ C $\quad$ D

1. I feel that I am person worthy of appreciation, at least as much as others.

2. I am convinced that I have good qualities

3. I am able to do things as well as most people

4. I have a positive attitude towards myself

5. In general I am satisfied with myself

6. I feel like I don't have much to be proud of.

7. In general, I am indeed to think that I am a failure

8. I wish I could feel more respect for myself.

9. There are times when, I really think I 'm useless

10. Sometimes I think I 'm not a good person

\section{Special features of the Kaerobic training plan as a unique aspect}

The training plan will aim to: decrease the BMI indexes in obese patients of the Danlí Regional University Centre through Kaerobic that includes elements of legs and arms.

Identifying elements of Kaerobic

It is a program of aerobic-martial physical activity with therapeutic purposes where they combine Karate-Do and Kick-Boxing with Aerobics to the rhythm of the music. KAEROBICS-DO literal meaning: $\mathrm{K}$ - This letter is 
used at the beginning, because it is the first letter of two essential martial arts (Karate-Do and Kick-Boxing) that are combined in the project.

Karate-Do (空手道): Karate-Do (空手道 / Karate-Dō, "the way of the empty hand") is a traditional martial art of Okinawan origin, and Japanese development. The person who practices this martial art is called a karateka or karateka. Karate-Do is characterized by the use of punches with fists, elbows, knees and kicks, although it does not restrict its repertoire only to them.

Karate-Do is a martial art in which force, breathing, balance and posture are coordinated, the correct hip twist and the joint connection of muscles and limbs, transferring a large part of the body weight and the centre of gravity to impact.

Generally, it is sought to defeat the adversary by means of a single forceful impact, similar to the thrust or the cut of a katana or Japanese saber.

Kick-Boxing (キックボクシング ). It is a contact sport of Japanese origin in which the fighting or combat techniques of boxing are mixed with those of some martial arts such as Karate and Thai Boxing.

Being thus related to the ancient art of Muay Thai but strikes with the elbow and knee are generally not allowed in competition, it is thus similar to modern Thai boxing or Thai Boxing.

Aerobics - This word is used because it is the name of a way to perform exercises continuously to the rhythm of the music, without stopping, from the beginning to the end and it is the form of execution of the aerobicmartial physical exercises of this alternative:

Aerobics or Aerobics is a type of aerobic sport that is performed to the sound of music. This sports modality brings together all the benefits of aerobic exercise, in addition to exercising physical capacities such as cardiovascular endurance, flexibility, coordination, orientation, rhythm, etc. Aerobics has been and continues to be very popular among women, although there are more and more men who practice it, leaving aside the issue of what is a women's sport. The rhythm of the aerobics sessions (classes) varies depending on the age of the public that practices it. The songs used mark the intensity in each moment of the class. Aerobics should also include warm-up exercises and stretching.

The coordinated union of all these elements together forms the kaerobic, which as a motivational factor in the subjects indirectly contributes towards character-building skills, self-defence, which acquires high motivational levels in individuals that allows them to complete the plan of training that was applied during 65 days.

\section{RESULTS}

The results obtained in the measurements after the application of the 65 days of work under the submission of the training plan based on Kaerobic, show the following expressions:

In the present graph it is observed that the waist-hip index after the application of the training and diet plan decreases, which shows that the cardiac risk decreases with the experiment carried out, in which a decrease of 0.3 is evidenced as a difference in reduction of the 1.7 that the 6 subjects submitted to 1.4 expressed as an average value to which it has been reduced, in this sense it is expressed in the following graph. 


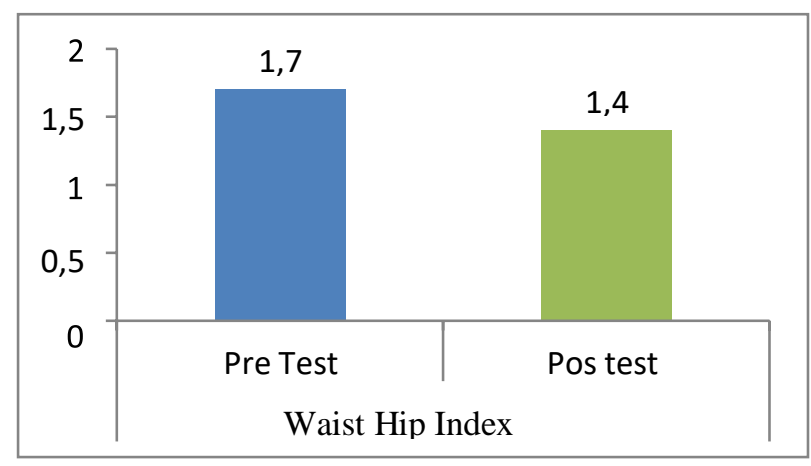

Figure 1. Waist Hip Index chart.

The assessment of the result of the BMI, which was in the group above 39 of BMI, being in the values indicated for obese in both sexes, we take into account that after the application of the training plan and the diet regimen it was achieved lose in most cases to overweight, reaching an overall group average of 26.8 as shown in the graph below:

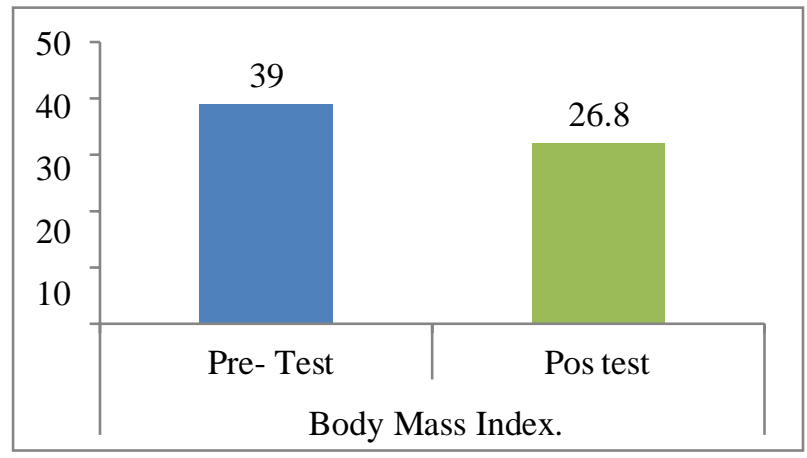

Figure 2. Body Mass Index graph.

Regarding the $\%$ of fat, it is evidenced that this low from $38 \%$ to $31.8 \%$ after the application of the training plan and the client in the investigated individual, in this sense, it is recognized that they still maintain high values of body fat, being Thus, the differences acquired in the reduction of body weight according to the BMl, are valued in residual weight where the reduction of body fluid accumulation significantly influences; Below are the results obtained in the two moments that the percentage of body fat is evaluated, where it has been reduced from $38 \%$ to 31.8 as a group average.

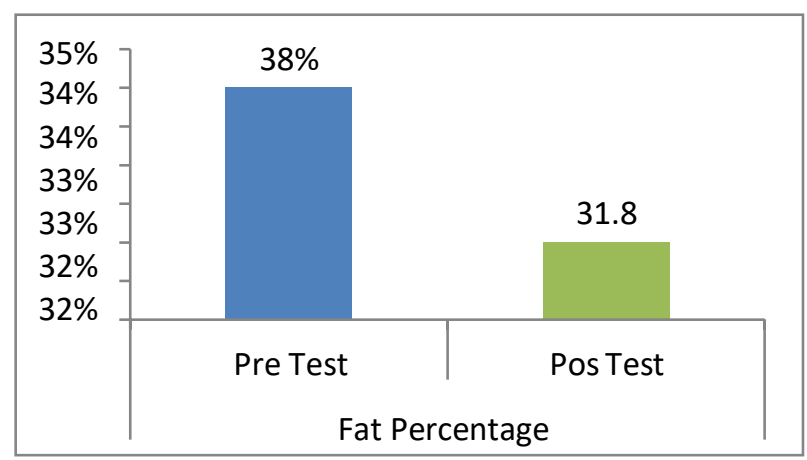

Figure 3. Graph of fat percentage. 


\section{Psychological. Self esteem}

Regarding the psychological aspect, the self-esteem aspect behaved in values referring to the criterion of disagreement and adequate, it is important to emphasize that this indicator has an evaluative tendency with an inclination towards negative values.

Taking into account as a multidisciplinary research, comparisons are established with the results of the blood chemistry tests of cholesterol, glucose, uric acid, HDL and LDL, all showed favourable transformations according to the doctor who attends them, as a group the results shown are taken into account in the graphs that appear below:

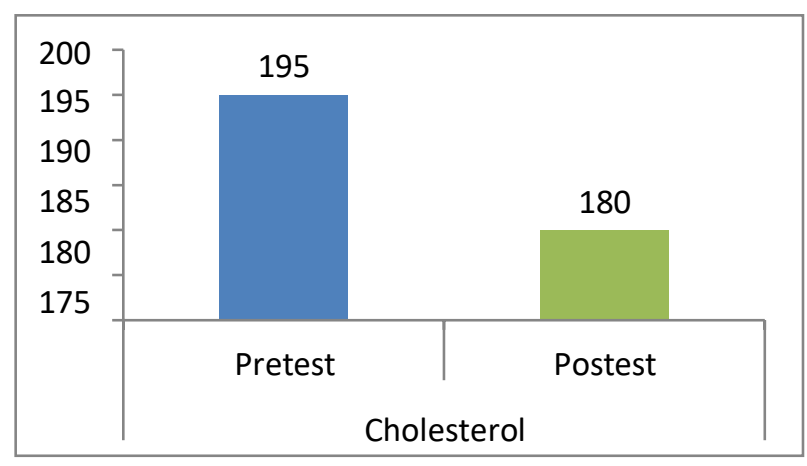

Figure 4. Cholesterol behaviour graph.

It is evidenced that the cholesterol from 195 dropped to 180 after the experiment carried out, which reduces the cardiac risk in the patient investigated.

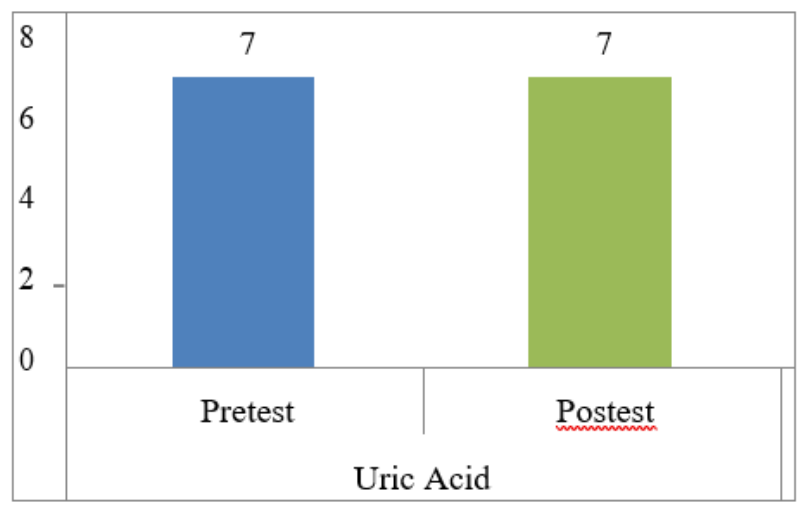

Figure 5. Behaviour of uric acid.

It is evident that after the application of the experiment, uric acid remained in normal ranges, so there are no organic alterations in the individual analysed. 


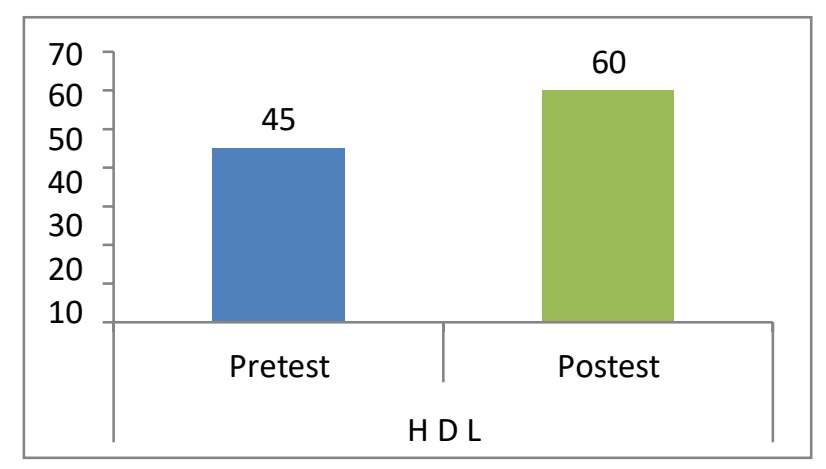

Figure 6. Behaviour of HDL.

At the end of the experiment in the individual investigated, it is evidenced that good cholesterol increased, showing inversely proportional to bad cholesterol. Indicating lower cardiac risk in the patient.

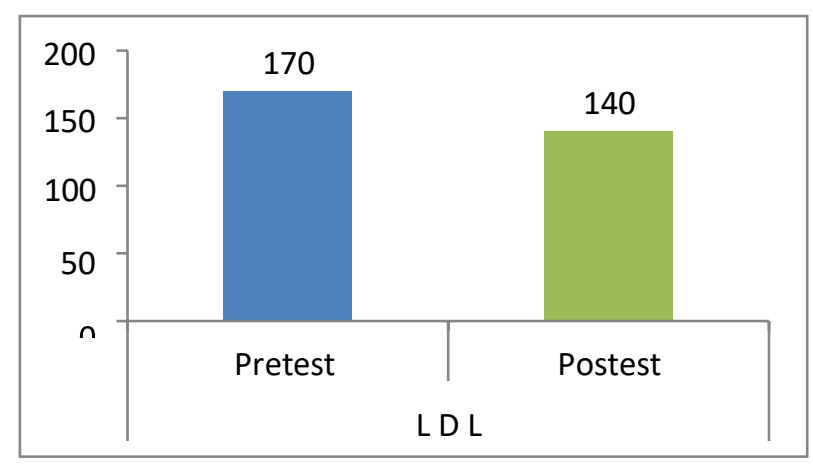

Figure 7. Behaviour of LDL.

At the end of the experiment in the investigated individual, it is evident that bad cholesterol decreased, showing inversely proportional to good cholesterol. Indicating lower cardiac risk in the patient.

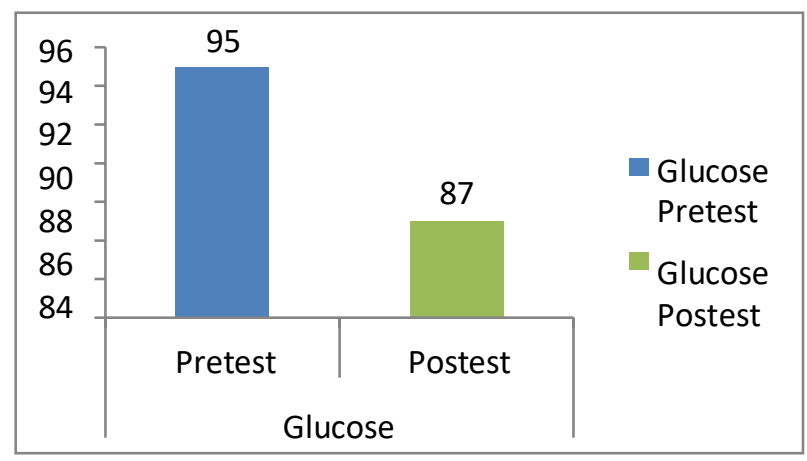

Figure 8. Glucose behaviour.

Changes in blood glucose were observed in the post-test, since after the experiment it decreased from 95 to 87 , an aspect of great interest since it shows that physical exercise is of great importance to avoid diseases that have to do with this indicator. 


\section{DISCUSSION}

The different theoretical arguments reviewed at the international and national level show us that a person with a personalized physical exercise plan and diet tends to lose mass and holistically improve in a functional way. Aspects that were generated in our patient in experiment, without being absolute in the arguments reviewed, since in 3 months under 10 kilograms, it is also possible to state that the normal should be 8 kilograms per month, however, our patient did not comply with $100 \%$ the planned physical exercise plan, as well as an alien variable that we did not monitor was diet.

Regarding physical activity, the waist-to-hip index decreases after the application of the training and diet plan, which shows that the cardiac risk decreases with the experiment carried out. In the body mass index after the application of the training and diet plan it decreases, which shows that the stated index has been reduced and therefore the mass of the individual studied. Regarding the $\%$ of fat, it is evidenced that it fell from $34 \%$ to $32 \%$ after the application of the training and diet plan in the individual investigated.

The psychological aspect of self-esteem did not improve; however, this aspect is considered normal as it is favourable that they still feel dissatisfied with their body weight and morphology.

The tests that measure blood chemistry all improved for optimal functioning of the body of the patient under study, which shows that physical exercise and diet were acceptable for the process of improving the health of the individual under study.

From the point of view of the training plan based on Kaerobic, we consider that this proposal can be adapted depending on the real situations that arise and propose this research as a bibliographic reference document for the study of physical activity and health in physical, mental and medical culture at UNAH.

\section{CONCLUSION}

The training plan based on Kaerobic allows to have positive effects on the physical condition of the subjects sampled at the UNAH-TEC-Danlí Regional University Centre, therefore, it can be applied to other samples with similar characteristics and in other contexts such as they are the community or spaces focused on physical rehabilitation.

\section{REFERENCES}

Barceló, A, y Borroto, G. (2001). Estilo de vida factor culminante en la aparición y tratamiento de la obesidad. Rev Cubana Invest Biomed p. 20(4):287-95.

Berdasco G. A. (2002) Evaluación del estado nutricional del adulto mediante la antropometría. Rev Cubana Aliment Nutricion16(2):146-52.

Booth M L, Hunter C, Gore C J, Bauman A, Owen N. The relationship between body mass index and waist circumference: implications for estimates of the populations prevalence of overweight. Int $\mathrm{J}$ Obes Relat Metab Disord 2000;24(8) 1058-61. https://doi.org/10.1038/sj.ijo.0801359

Cole T J., Bellizzi M.C., Fiegal K.M.,Dietz,W.H. (2000) Establishing a standard definition for child overweight and obesity worldwide: international surverey.BMJ;320:1240-3. https://doi.org/10.1136/bmi.320.7244.1240 
Guerrero-Millo M. Adipose tissue hormones. J Endocrinol (2002) NOV, 25(10):855-61 Bray GA. Overweight its risking fate: definition, classification, prevalence and risk. Ann NY Acad Sci 1987;499:14-28.

Nogueras, N. (2002) . Orígenes y evolución de la Fisioterapia. Proyecto Docente.

Navarro E., De la Paz, P.L. (2008). Actividad Física Comunitaria. Editorial Deportes. La Habana, Cuba. National Institutes of Health Consensus Development Panel on the Health implications of Obesity. (2002) Health Implications of Obesity. Ann Intern Med 1985; 103: 1073-1077. Revista Panamericana. https://doi.org/10.7326/0003-4819-103-6-1073

Scarcella C, Depress J P. Treatment of obesity: the need to target attention on high-risk patients characterized by abdominal obesity. Cad Saude Publica 2003;19(suppl 1): S7-S19. 